substantially influence a child's ability to choose a safe route and to cross roads safely.

Methods Two hundred and forty 7- and 8-year-old children completed a series of road crossings in a semi-immersive virtual environment by watching traffic and stepping off of a curb onto a trigger plate when they felt it was safe to cross. Road crossing performance was assessed via measures of attention, wait time, movement timing, and crashes. Route selection was assessed by asking children to choose the safest route to a destination using vignettes and a tabletop model. BMI was calculated using BMIfor-age growth charts for boys and girls.

Results Children with higher BMI were riskier than peers with lower BMI on measures of waiting before crossing, time to spare relative to oncoming vehicles, and crashes with virtual traffic. BMI was not related to route selection.

Conclusions Childhood obesity is an important risk factor for pedestrian injury. In particular, children with high BMI had difficulty perceiving and acting on gaps in traffic.

\section{CHILD DEATH REVIEW: AN EFFECTIVE APPROACH TO UNDERSTANDING AND PREVENTING CHILD INJURY DEATHS}

${ }^{1}$ Theresa Covington, ${ }^{2}$ Jared Parrish, ${ }^{3}$ Patricia Schnitzer. ${ }^{1}$ National Centre for Fatality Review; ${ }^{2}$ Univeristy of N. Carolina and Alaska Department of Public Health; ${ }^{3}$ National Centre for Fatality Review

\subsection{6/injuryprev-2016-042156.660}

Background Child Death Review (CDR) is the multi-disciplinary case review of preventable child deaths. All fifty states in the United States, several Indian Tribes and Guam have well established CDR programs. A number of other countries, including Australia, New Zealand and the United Kingdom also have CDR programs. There is wide variation in the quality of CDR reviews. A majority of states utilise the National CDR Case Reporting System, a standardised system that collects and allows analysis of findings from the reviews. This educational session will present. Objectives

- Understand the purpose and function of child death review.

- Develop knowledge and skills in establishing a multidisciplinary CDR team that reviews all injury deaths of children ages 0-19.

- Develop skills in conducting an effective review team meeting.

- Develop skills in developing recommendations for evidencebased prevention strategies. using CDR findings and data.

Results This session is designed to provide an overview on CDR, a description of the status of CDR in the United States and other countries, and then provide information on developing and implementing quality CDR reviews. Attendees will be given program materials from the US CDR Resource Centre at the National Centre of Fatality Reviews. Participants will participate in a mock case review of child injury deaths including infant suffocation, drowning, motor vehicle and child abuse. The intent of the session is to build capacity of participants to effectively develop and manage their own review programs within their own local context. Data from the US CDR Case reporting system will be shared so that participants understand how review data can be used effectively to develop and implement policies, practices and programs that prevent child injury deaths.

Conclusions is an effective approach to galvanising community and state level injury prevention programs and policy.

\section{REDUCING THE RISK OF CHOKING IN CHILDREN: A MOOC (MASSIVE OPEN ONLINE COURSE) TO TEACH HOW TO PREPARE FOOD}

${ }^{1}$ Dario Gregori, ${ }^{2}$ Solidea Baldas, ${ }^{2}$ Luca Rosati, ${ }^{1}$ Giulia Lorenzoni. ${ }^{1}$ University of Padova, Italy; ${ }^{2}$ Prochild ONLUS, Italy

\subsection{6/injuryprev-2016-042156.661}

Background To try to respond to the need for education initiatives targeted at adults supervisors, with an easy and accessible communication format, a MOOC (massive open online course) for disseminating information on food choking injuries, has been realised.

Methods The project consists of a series of informative videos freely available on a dedicated website. The contents are intended for an audience mainly of parents, educators and childcare professionals. The video contents are realised on the basis of data provided by the Susy Safe, an International registry of foreign body injuries in children aged 0-14. Currently, it has collected over 25.000 cases. The information regarding the foreign body details and the circumstances of the injury allows the identification of the food foreign bodies causing injuries with greater frequency. Presently Food bones, Nuts and Seeds and grains have the highest incidence.

Results Following the recommendations provided by the International Guidelines for food preparation, the videos provide basic information addressed to those who have the task of preparing food for children, explaining in a clear and as simple as possible manner how to reduce the risk presented by certain foods. With simple measures even the most dangerous foods can be safely consumed by children. In each video a specific topic, closely related to the problem of food choking in children is clearly addressed (epidemiology, children anatomy, obstruction mechanism, food preparation) by a field expert. According to the Susy Safe data, almost $40 \%$ of injuries happened under adults' supervision, showing a lack of information and the need to implement specific educational campaigns targeted to families and supervisor.

Conclusions The MOOC, available at www.safefood4children. org, has been actively attended by families and firms in the food supply chain. This testifies the interest and the need for education in the field of choking injuries prevention.

\section{Traffic Safety}

\section{Post Tue 2.5}

\section{MOTORCYCLE HELMET AND CAR SEAT BELT USE PATTERNS IN DELHI, INDIA: IMPLICATIONS FOR TRAFFIC SAFETY INTERVENTIONS}

Dinesh Mohan. Indian Institute of Technology Delhi, India

\subsection{6/injuryprev-2016-042156.662}

Background In 1993 The Delhi government made it mandatory for all MTW riders to wear helmets and use of seatbelts for front seat passengers of cars in 2002. It became compulsory for all cars in 2002 to be equipped with seatbelts in the rear seats, but not their use. In 1999 helmet use was made optional for female MTW riders and the notification was reversed in September 2014 and helmet use became mandatory for all MTW riders again. In this paper we report the motorcycle helmet and car seat 